\title{
Temporal trends of maternal near miss in Brazil between 2000 and 2012
}

\author{
Beatriz Aguiar da Silva Carvalho 1
}

https://orcid.org/0000-0002-8057-886X

Ana Gabriella Bandeira Freire Andrade 2

https://orcid.org/0000-0002-8023-0134

Andreza Saboia Dantas 3

https://orcid.org/0000-0001-8620-9603

Ingrid Medeiros de Figueiredo 4

https://orcid.org/0000-0001-8742-2924

Jéssica Alves da Silva 5

https://orcid.org/0000-0002-9850-6223

Tatyana Souza Rosendo 6

https://orcid.org/0000-0001-6131-3201

Angelo Giuseppe Roncalli 7

https://orcid.org/0000-0001-5311-697X

1-5 Departamento de Medicina. Centro de Ciências da Saúde. Universidade Federal do Rio Grande do Norte. Av. Senador Salgado Filho, 300. Campus Universitário Lagoa Nova. Natal, RN, Brasil. CEP: 59.078-970. E-mail: beatrizaguiarcarvalho@gmail.com

6 Departamento de Saúde Coletiva. Universidade Federal do Rio Grande do Norte. Natal, RN, Brasil.

7 Programa de Pós-graduação em Saúde Coletiva. Universidade Federal do Rio Grande do Norte. Natal, RN, Brasil.

\begin{abstract}
Objectives: to identify the temporal trends and regional variations in maternal near miss in Brazil.

Methods: ecological study of temporal trends. The units of analysis are in the States, the regions and Brazil, between 2000 and 2012, the dependent variable being the maternal near miss rate (MNMR), calculated from the records of the Sistema de Informações Hospitalares do Sistema Único de Saúde (SIH-SUS) (National Health Hospital Information System).Regression analysis using Joinpoint regression software, version 4.1.0. was applied to analyze morbidity trends.

Results: the main result of this study was a finding on an increase rate trend in maternal near miss in Brazil, between 2000 and 2012. This trend behaves differently depending on the development level of the region studied, presenting a positively higher increase in less developed regions and states.

Conclusions: there is an increasing trend in maternal near miss rates in Brazil. The SIHSUS may be an important instrument in identifying and monitoring maternal morbidity. Furthermore, investments in more effective public policies are needed to reduce inequalities and improve human development, both of which have influenced the chain of events related to maternal health.

Key words Near miss, Maternal mortality, Temporal distribution, Morbidity
\end{abstract}

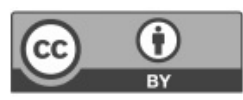




\section{Introduction}

Despite the undeniable technological advances in recent decades, around 289,000 women died of complications during pregnancy, childbirth and puerperal every year. In spite of a $45 \%$ decline in relation to the values in 1990's, although it is acknowledged that $98 \%$ of these deaths occur in developing countries, and the causes are considered preventable.

Analyzing the spectrum which ranges from a healthy pregnancy to death, this may identify a series of conditions and harmful consequent events for women. Within these events include maternal near misses (MNMs), defines as a woman who nearly died but survived a complication that occurs during pregnancy, childbirth or puerperal2 Although maternal death has been chosen as one of the Objectives of the Millennium, health services cannot ignore maternal morbidity and its effects on women's health. ${ }^{3}$

The highest maternal near miss rates are reported in developing countries ${ }^{4}$ and the causes related to maternal near miss in these countries are similar to those of maternal mortality.2,5 A number of factors that are determinants of mortality are also relevant for morbidity, such as the lack of adequate access to prenatal and childbirth, in addition to the absence of specific technological support, such as an intensive therapy unit or even emergencial blood transfusions. 6 The increase in maternal morbidity rates, especially in low-income countries, demonstrates the inability of the health services to offer quality in maternal care. 7

In the context of maternal near miss, there is a predominance of hospital-based studies, 8,9 although surveys have also been conducted.10,11 In Brazil, with a view to produce population estimates, some studies analyzed the databases from the Sistema de Informação Hospitalar (SIH) and the Sistema de Informação de Mortalidade (SIM) and the Sistema Único de Saúde (SUS) (Hospital Information System, the Mortality Information System and the National Public Health System), suggesting forms to identify cases by correlating Mantel et al.,12 Waterstone et al.,13 and $\mathrm{WHO}^{2}$ criteria with the use of the procedure codes in obstetric care and diagnostic codes based on the International Classification of Diseases-10th revision (ICD-10). ${ }^{14}$ 17

The use of secondary data from the SIH seems to be a good alternative for the study on maternal near miss because it allows to identify any of the cases and the possible associated factors. 15,16 Moreover, these data have a good coverage, since most childbirths in Brazil occur in hospitals and $70 \%$ of these are at through the National Public Health System (SUS) or its affiliated network. 18

In regard to this, studies are needed to determine the maternal near miss rate based on the availability of the data through from the Sistemas de Informação de Saúde (Health Information System), since the study of these events may be useful in improving obstetric treatment and epidemiological surveillance, and enabling managers to prioritize health investments. 19 The prevalence on maternal near miss analysis is also important to assess the impact of public policies implemented to enhance maternal health. 20

Brazil is one of the countries that considerably reduced maternal mortality in the 1990s; however, this decline began to decline in the 2000s.21,22 Therefore, it is important to observe the behavior on the maternal near miss tendency, analyzing its behavior in regions with different economic and social development. The hypothesis of the present study was that there would be a downward trend in maternal near miss over time, mainly in the most developed areas.

As such, the aim of this study was to identify the temporal trends and regional variations in maternal near miss in Brazil using registrations from the Sistema de Informações Hospitalares do Sistema Único de Saúde (SIH-SUS) (National Health Hospital Information System).

\section{Methods}

This is an ecological study of temporal trends, in which the units of analysis are in the states, regions and Brazil. Brazil has 26 states and one Federal District, distributed into five regions (North, Northeast, Central-West, South and Southeast) with different socioeconomic characteristics, the South and Southeast are the most developed regions. The period analyzed was between 2000 and 2012. The start of the period was established based on the search criteria from the Sistemas de Informação Hospitalares, (Hospital Information Systems), described later on, which could be applied from the year 2000 onwards, while 2012 was the last year considered to observe the trends due to the fact that the data collection was initiated in 2013 and the satisfactory analysis of the outcome could be conducted over time using the observations of 13 trend points.

The dependent variable was the maternal near miss rate (MNMR). The information used to calcu- 
late this rate for each unit of analysis was obtained from the SIH-SUS records available at the DATASUS website (www.datasus.gov.br). For each year of the trend, MNMR was calculated by dividing the cases that occurred during that year by the number of women hospitalized for obstetric procedures in the same year. Thus, MNMR = number of near miss cases/number of women hospitalized for obstetric procedures $* 1000$, excluding maternal deaths.

To calculate MNMR, we selected all the women from the SIH-SUS databank aged between 15 and 49 years, living in Brazil and hospitalized in public health institutions, affiliated or contracted by the National Public Health System (SUS). These women were identified from the principal diagnosis field that contains the ICD-10 code and the field containing the procedures performed at SIH-SUS. Thus, all the hospitalized women during pregnancy, childbirth or puerperal period diagnosed in Chapter $\mathrm{XV}$ or group "O" (causes related to pregnancy, childbirth or puerperal) of the ICD-10 and/or the "procedures performed" field that were filled out with codes related to the pregnancy-puerperal period were identified and composed to determine the denominator of the near miss rate by estimating the number of childbirths. A sampling calculation was unnecessary because all the women registered at SIH-SUS were identified by using these criteria for each year and for each unit of analysis.

Next, the near miss cases were selected to be included in the numerator based on the criteria proposed by Waterstone et al.,13 who classified severe preeclampsia, eclampsia, hemorrhage, sepsis, uterine rupture and HELLP syndrome as maternal near miss markers. In order to identify near miss cases at SIH-SUS, the main diagnosis field with the ICD-10 code was used. Sousa et al. ${ }^{14}$ correlated the ICD-10 codes with the marker conditions suggested by Waterstone et al. 13 The association between ICD10 codes and the criteria of Waterstone et al.13 are described in Table 1. Since there is no ICD-10 corresponding to HELLP syndrome, the acronym used to describe the condition of patients with severe preeclampsia that exhibit hemolysis $(\mathrm{H})$, elevated liver enzymes (EL) and low platelet count (LP), this marker condition was not used to identify near miss in our study.

Furthermore, it is important to clarify that although $\mathrm{WHO}^{2}$ criteria are currently applied in the studies, $15,19,20$ they were not used to identify cases because of the difficulty in correlating these criteria with ICD-10 diagnosis and SIH-SUS procedure codes. Waterstone et al. 13 criteria were selected to identify maternal near miss cases rather than those of $\mathrm{WHO}^{2}$ because clinical conditions are easy to correlate to ICD-10 codes, which constitutes the main diagnostic field contained in SIH-SUS.

Joinpoint regression analysis was applied to determine maternal morbidity trends by using the Joinpoint Regression Program (National Cancer Institute, Bethesda, Maryland, USA), version 4.1.0. The aim of the analysis was to identify the occurrence of possible joinpoints with a change in the trend. The method applied identified joinpoints based on the model with a maximum of 3 changing points. The final model selected was the adjusted better with the Annual Percentage Change (APC) based on the trend of each segment, determining whether these values are statistically significant at a $95 \%$ confidence level. The significance tests applied are based on the Monte Carlo permutation method and annual percentage variation in the ratio, using the logarithm of the ratio.

The research adhered to the criteria and requirements of the Resolution $n^{\circ} 466 / 12$ of the Conselho Nacional de Saúde (CNS) (National Health Council) and followed the recommendations of the Research Ethics Committee at the Hospital Universitário Onofre Lopes (HUOL) at the Universidade Federal do Rio Grande do Norte (UFRN) in which this project was submitted and approved under the protocol number 496657.

\section{Results}

The maternal near miss rates in Brazil presented a significant trend increase until 2004 (Figure 1). From then on, the same trend was observed, with a lower increase and not significant (Table 2). The number of near miss cases and hospitalizations for obstetric procedures in Brazil during the period analyzed was $1,059,988$ women and $33,166,365$ were identified for obstetric hospitalization procedures, however, the rate for the period was of 31.96/1000 obstetric procedures.

Analysis in the North region identified a significant trend with a large increase until 2004, when this trend began to decrease (Figure 2). Most of the North states presented similar behavior to that of the region, as Acre, Amapá and Tocantins these with the largest increases until the first joinpoint. A different behavior was observed in Roraima and Rondônia, where the first increase was observed a decreased trend even being non-significant with a change from 2007 onwards, and then observed a significant increase in Rondônia (Table 2).

In general, the Northeast and its states displayed 
Table 1

Waterstone et al. ${ }^{13}$ criteria in relation to ICD-10 codes to identify maternal near miss cases in the SIH, according to Sousa et al.14 Natal-RN, 2017.

\begin{tabular}{lcc}
\hline $\begin{array}{l}\text { Waterstone et al.13 } \\
\text { criteria/markers }\end{array}$ & $\begin{array}{c}\text { General characterization } \\
\text { of diagnoses }\end{array}$ & $\begin{array}{c}\text { General characterization of } \\
\text { the procedures performed }\end{array}$ \\
& (ICD-10 codes) & \\
\hline
\end{tabular}

Severe pre-eclampsia

HELLP syndromea

Severe hemorrhage

Severe sepsis

Uterine rupture
Moderate, severe or nonspecific pre-eclampsia; pre-existing hypertensive disorder with overlapping proteinuria

[011;014.0;014.1;014.9]

Eclampsia during pregnancy, labor or childbirth [015;015.0;015.1;15.2;015.9]

NA

Incomplete and complicated miscarriage by delayed or excessive hemorrhage; premature placental abruption

[D62;003.1;003.6;004.1;004.6;005.1;005.6;O

$06.1 ; 006.6 ; 007.1 ; 007.6 ; 008.1 ; 044.1 ; 045.0 ; 04$ 5.8;045.9;O46;046.0;046.8;046.9;067.0;067.8 ;067.9;069.4;072;072.0;072.1;072.2]

Infection; sepsis; complicated miscarriage by genital tract infection; peritonitis; salpingitis [A02.1;A22.7;A26.7;A32.7;A40;A40.0;A40.1;A4 0.2;A40.3;A40.8;A40.9;A41;A41.0;A41.1;A41.2 41.3;A41.4;A41.5;A41.8;A41.9;A42.7;A54.8;B3 7.7;K35.0;K35.9;K65.0;K65.8;K65.9;M86.9;N70 0;N70.9;N71.0;N73.3;N73.5;O03.0;O03.5;O04.0 ;004.5;005.0;005.5;006.0;006.5;007.0;007.5; O08.0;008.2;008.3;041.1;075.3;085;086;086. $0 ; 086.8 ; 088.3 ; \mathrm{T} 80.2]$

Uterine rupture before or during labor: cesarean wound rupture [071.0;071.1;090.0]
Severe pre-eclampsia

Labor with eclampsia; eclampsia

NA

Hemorrhage during pregnancy

Post-cesarean operative wound infection childbirth or puerperal infection; sepsis; acute adnexal infection; post-cesarean peritonitis; peritonitis

ano code relative to the syndrome; NA= not assessed; $\mathrm{SIH}=$ Sistema de Informação Hospitalar (Hospital Information System). 


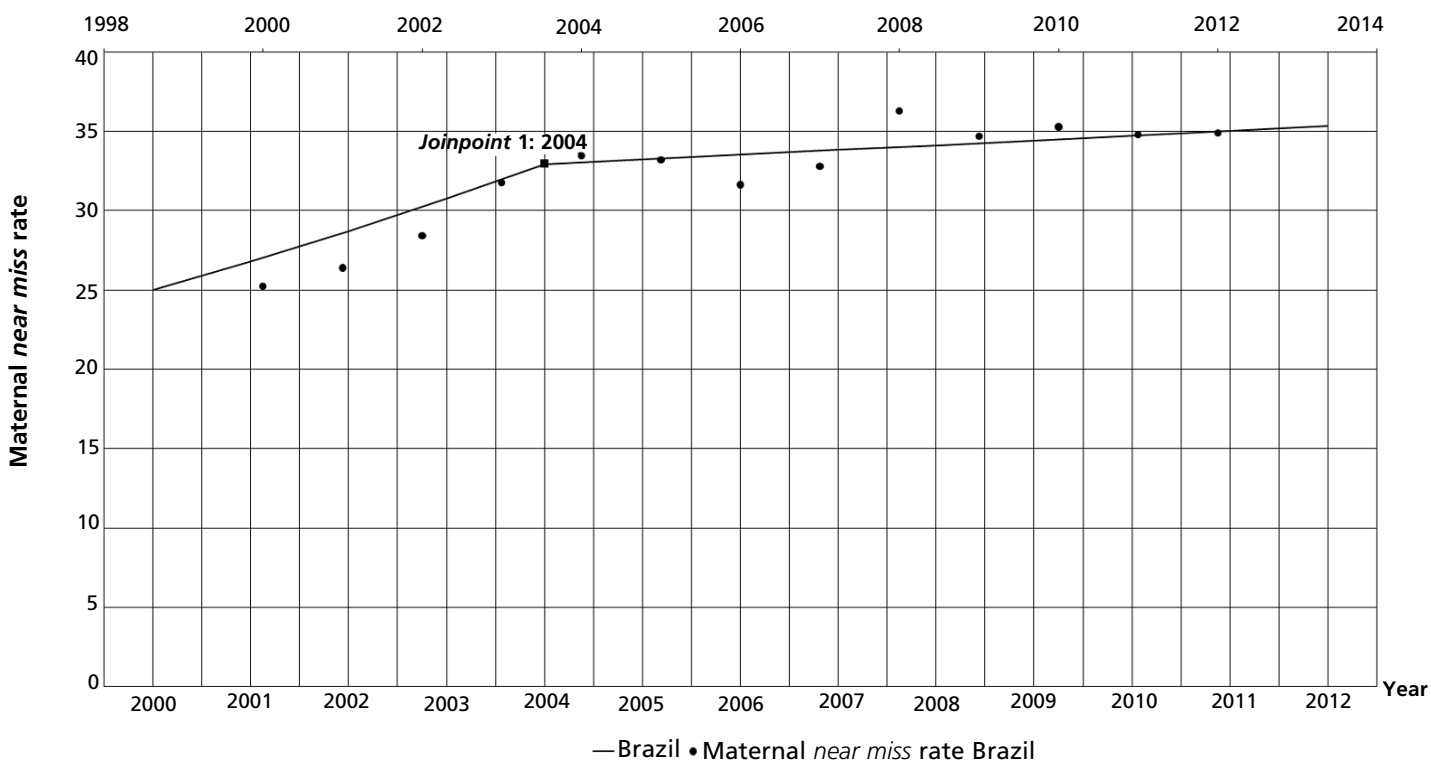

an increasing trend (Figure 2). Piauí, Rio Grande do Norte and Bahia presented changes in the decrease to the increased trend with a significant increase in the first two States and a decline in Bahia. Although Pernambuco and Ceará showed an increased trend throughout the period, although, we observed a higher increase until the first joinpoint. Maranhão, Alagoas, Paraíba and Sergipe presented a significant increase until the joinpoint and the change was nonsignificant in the decreased trend .

In an analysis in the Southeast observed a declining trend between 2000 and 2002 and 2008 and 2012, with the greatest decrease in the former period, even being non-significant (Figure 3). The analysis by States observed that nearly all of them presented a decreased trend. In São Paulo, there was a significant increase between 2000 and 2005, but a decline, also significant, from 2005 onwards. In Minas Gerais State presented a differently behavior with a significant increase between 2003 and 2012 (Table 2).

In the analysis in the South observed that from the 2003 joinpoint onwards, the trend declined significantly, approaching stability (Figure 3 ). In the States of Paraná and Santa Catarina presented a decreased trend from 2003 and 2004 onwards, respectively. Only in Rio Grande do Sul demonstrated a significant increase trend during the entire period (Table 2).
In the Central-West, after a period of increasing rates, the trend declined from 2009 onwards, even not being statistically significant (Figure 3 ). The same trend behavior was observed in the States of this region with a decrease from the first joinpoint which was only significant in the Federal District (Table 2).

\section{Discussion}

The main result of this study was a finding on an increase rate trend in maternal near miss in Brazil in the period of 2000 and 2012. Analysis by region was observed that those with lower socioeconomic development (North and Northeast) presented an increased trend, while the more developed counterparts (Central-West and Southeast) experienced a decreased trend after the last joinpoint. Regional differences in maternal near miss rates were also found in the literature. 4

In contrast to the maternal mortality behavior in Brazil, which has remained stable over the last ten years, ${ }^{21}$ maternal morbidity presented a positive and increasing trend, especially until 2004. This has been followed by a steady increased trend, but with a lower increase and non-significant. In this respect, there is a need to understand and discuss maternal morbidity, particularly based on official statistics. Furthermore, the health services must not underesti- 
Table 2

Temporal trends of maternal near miss in Brazil, Regions and the Federation Units: Annual Percentage Change (APC), confidence interval (Cl95\%) and joinpoint year. Natal - RN, 2017.

\begin{tabular}{|c|c|c|c|c|c|c|c|c|}
\hline & APC1 & $\mathrm{Cl} 95 \%$ & Joinpoint & APC2 & Cl95\% & Joinpoint & APC3 & $\mathrm{Cl} 95 \%$ \\
\hline BRAZIL & $7.2 \mathrm{a}$ & {$[3.5 ; 11.0]$} & 2004 & 0.9 & {$[-0.3 ; 2.1]$} & & & \\
\hline North & $38.0 \mathrm{a}$ & {$[31.8 ; 44.5]$} & 2004 & 0.6 & {$[-0.9 ; 2.3]$} & & & \\
\hline Acre & $352.4 a$ & {$[224.7 ; 530.5]$} & 2002 & -1.1 & {$[-3.6 ; 1.5]$} & & & \\
\hline Amapá & $70.7 a$ & {$[3.9 ; 180.5]$} & 2003 & -8.2 & {$[-16.2 ; 0.5]$} & & & \\
\hline Amazonas & $45.6^{a}$ & {$[31.6 ; 61.1]$} & 2006 & -5.8 & {$[-14.9 ; 4.2]$} & & & \\
\hline Pará & $16.6^{a}$ & {$[8.4 ; 25.5]$} & 2004 & 0.1 & {$[-2.4 ; 2.6]$} & & & \\
\hline Rondônia & -1.8 & {$[-7.6 ; 4.3]$} & 2007 & $10.9 a$ & {$[0.2 ; 22.8]$} & & & \\
\hline Roraima & -2.9 & {$[-23.6 ; 23.4]$} & 2007 & 41.3 & {$[-5.4 ; 111.2]$} & & & \\
\hline Tocantins & $64.5^{a}$ & {$[30.6 ; 107.2]$} & 2003 & $5.1 \mathrm{a}$ & {$[0.7 ; 9.6]$} & & & \\
\hline Northeast & $3.6 a$ & {$[2.5 ; 4.7]$} & & & & & & \\
\hline Alagoas & $28.7 a$ & {$[15.3 ; 43.8]$} & 2004 & -3.2 & {$[-6.8 ; 0.6]$} & & & \\
\hline Bahia & $-9.1 a$ & {$[-13.9 ;-4.0]$} & 2006 & 3.1 & {$[-2.4 ; 8.9]$} & & & \\
\hline Ceará & $97.4 \mathrm{a}$ & {$[58.7 ; 145.6]$} & 2002 & $4.2 \mathrm{a}$ & {$[2.4 ; 6.0]$} & & & \\
\hline Maranhão & $16.8^{a}$ & {$[6.2 ; 28.4]$} & 2006 & -7.7 & {$[-16.1 ; 1.5]$} & & & \\
\hline Paraíba & $49.1 \mathrm{a}$ & {$[22.7 ; 81.1]$} & 2005 & -4 & {$[-14.5 ; 7.9]$} & & & \\
\hline Pernambuco & $39.6 a$ & {$[11.9 ; 74.0]$} & 2003 & $6.4 a$ & {$[2.2 ; 10.8]$} & & & \\
\hline Piaui & -8.1 & {$[-22.0 ; 8.2]$} & 2005 & $16.3 \mathrm{a}$ & {$[5.4 ; 28.2]$} & & & \\
\hline Rio Grande do Norte & -2.1 & {$[-6.7 ; 2.8]$} & 2007 & $18.4^{a}$ & {$[9.1 ; 28.4]$} & & & \\
\hline Sergipe & $28.5^{a}$ & {$[8.9 ; 51.0]$} & 2004 & -0.5 & {$[-6.0 ; 5.2]$} & & & \\
\hline Southeast & -3.9 & {$[-16.5 ; 10.5]$} & 2002 & 1.2 & {$[-1.9 ; 4.4]$} & 2008 & -1.5 & {$[-5.7 ; 3.0]$} \\
\hline Espírito Santo & -1.6 & {$[-4.8 ; 1.6]$} & & & & & & \\
\hline Minas Gerais & $-14.1 \mathrm{a}$ & {$[-22.2 ;-5.2]$} & 2003 & $3.6 \mathrm{a}$ & {$[1.7 ; 5.5]$} & & & \\
\hline Rio de Janeiro & -1.8 & {$[-5.2 ; 1.8]$} & & & & & & \\
\hline São Paulo & $8.3 \mathrm{a}$ & {$[4.4 ; 12.2]$} & 2005 & $-3.3 a$ & {$[-5.4 ;-1.2]$} & & & \\
\hline South & 13.2 & {$[-1.2 ; 29.8]$} & 2003 & 0.3 & {$[-2.2 ; 2.8]$} & & & \\
\hline Paraná & 9.1 & {$[-12.3 ; 35.6]$} & 2003 & -0.4 & {$[-4.3 ; 3.6]$} & & & \\
\hline Rio Grande do Sul & $4.2^{a}$ & {$[2.7 ; 5.7]$} & & & & & & \\
\hline Santa Catarina & $18.9 a$ & {$[1.8 ; 38.9]$} & 2004 & -3.8 & {$[-8.8 ; 1.5]$} & & & \\
\hline Central-West & 27.0 & {$[-1.2 ; 63.1]$} & 2002 & 2.9 & {$[-1.4 ; 7.3]$} & 2009 & -9.9 & {$[-20.5 ; 2.1]$} \\
\hline Federal District & 31.8 & {$[-22.8 ; 124.9]$} & 2002 & $-5.5^{a}$ & {$[-9.3 ;-1.5]$} & & & \\
\hline Goiás & $5.8^{a}$ & {$[1.6 ; 10.0]$} & 2008 & -8.5 & {$[-18.5 ; 2.6]$} & & & \\
\hline Mato Grosso & $52.6^{a}$ & {$[21.6 ; 91.5]$} & 2004 & -2.2 & {$[-9.6 ; 5.8]$} & & & \\
\hline Mato Grosso do Sul & $7.8^{a}$ & {$[3.0 ; 12.7]$} & 2009 & -3.8 & {$[-24.8 ; 23.0]$} & & & \\
\hline
\end{tabular}

a APC $p<0.05$. 


\section{Figure 2}

Temporal trend of maternal near miss rates in the North and Northeast regions. Natal-RN, 2017.

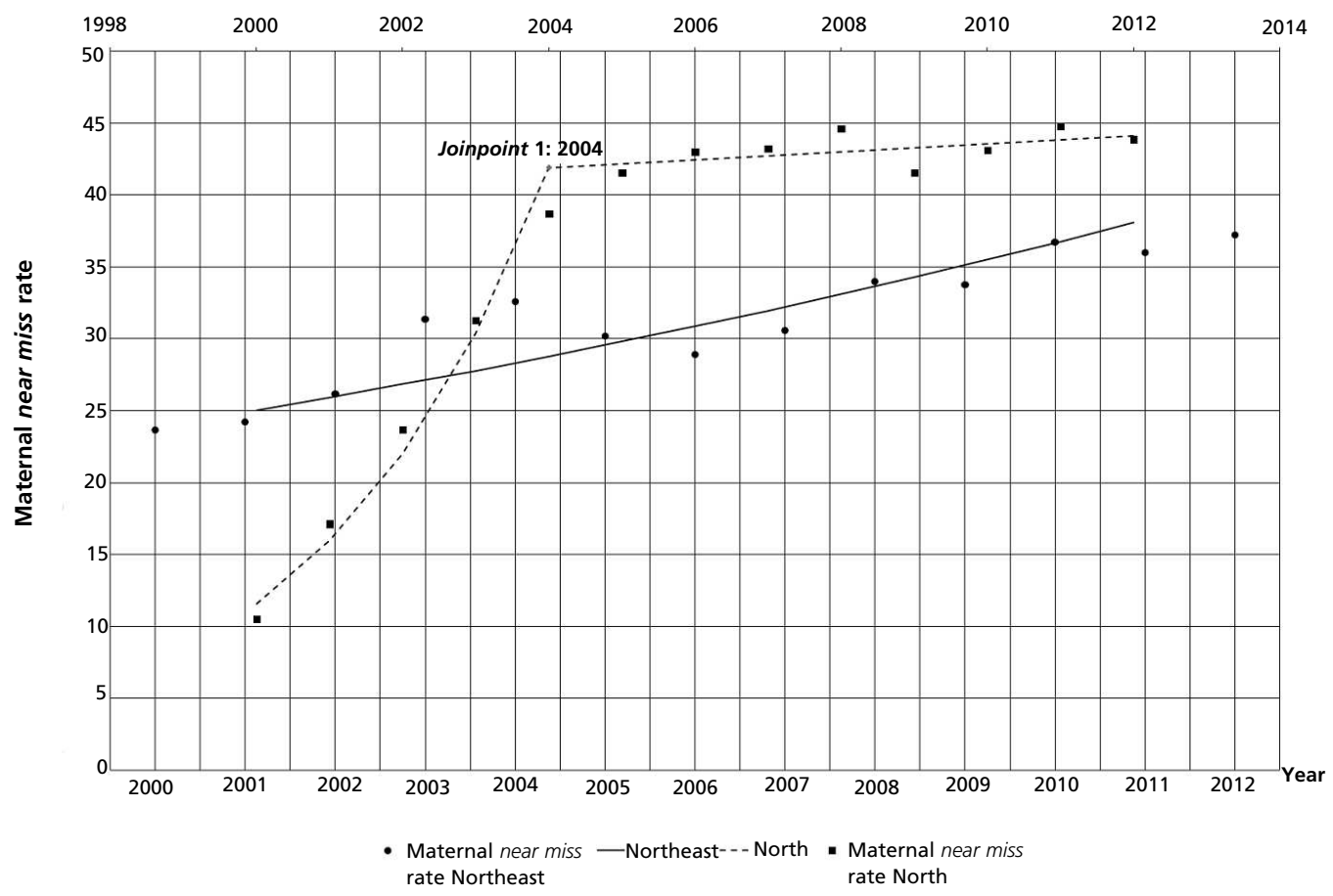

Figure 3

Temporal trend of maternal near miss rates in the Southeast, South and Central-West regions. Natal-RN, 2017.

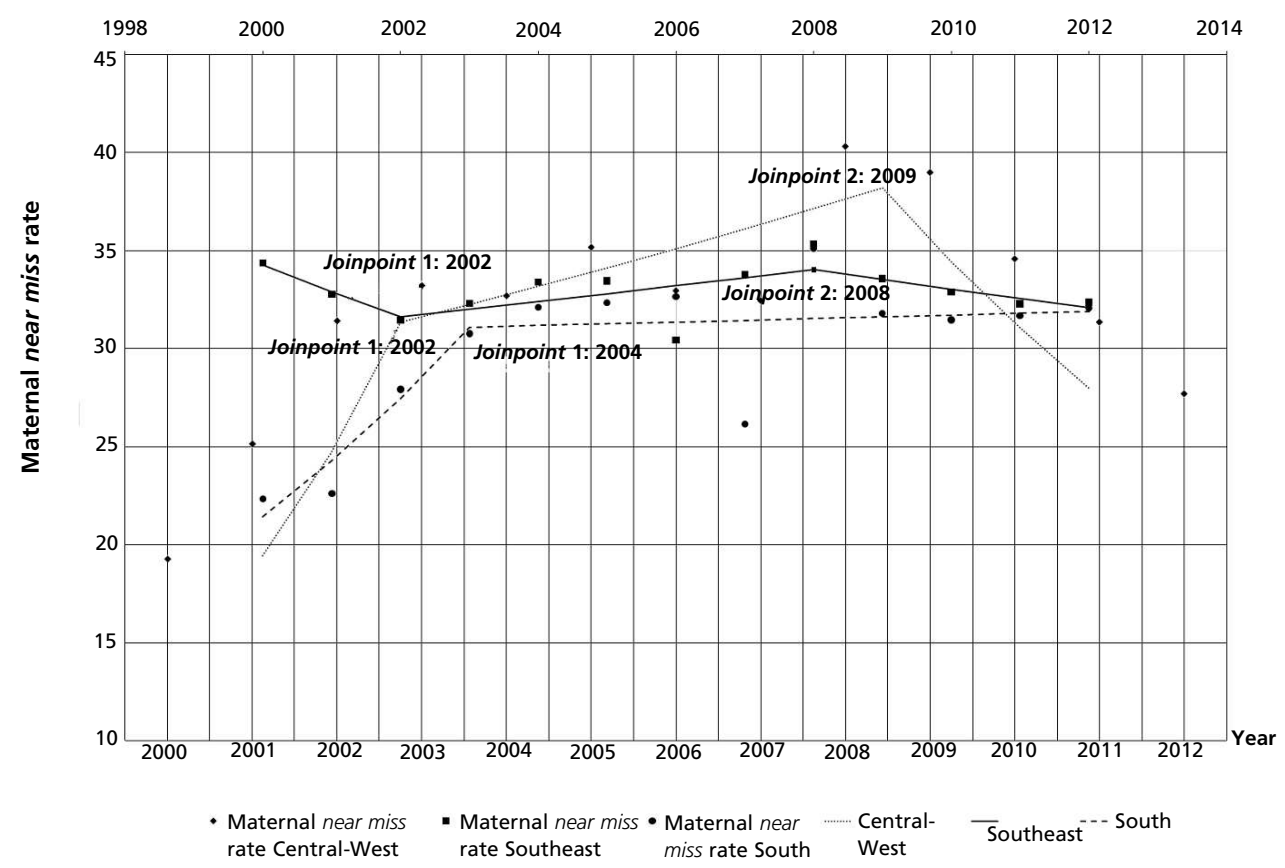


mate these events, which are more frequent than maternal death and may have serious consequences for women. ${ }^{3}$

Interestingly, the decreased trend in near miss rates in the most developed regions (Central-West and Southeast) only occurred after 2009 and 2008, respectively. Until then, the trend in the CentralWest was increasing, but decreased in the Southeast between 2000 and 2004. This may be due to the origin of the data used in this research, which were obtained from the information systems. In the first periods of the trend, the increasing rate was most likely influenced by the improvement in SIH registrations.

As observed in the Central-West, the decreased rates in the Southeast may be explained by the effective improvement in the maternal health care in the region. The Southeast was one of the regions that benefitted most from the change in the obstetric care model, due to the increase in good practices in this area.23 Moreover, the Comitês de Mortalidade Materna e Infantil (Maternal and Infant Mortality Committees) in all the regions of São Paulo State have contributed in decreasing maternal mortality in this study. 24 Only Minas Gerais State presented an increase in maternal near miss rates between 2003 and 2012, which may be due to the similarity of the geo-economic between the North part of the State and those in the Northeast region.

Despite being one of the regions with the highest human development levels in the country, the South of Brazil presented an increased trend until 2003, followed by relative stability. Analysis by States revealed that only Rio Grande do Sul presented a rising trend throughout the entire period of analysis, which likely accounts for the absence of a rate decrease in the South. A number of studies in developed regions have reported an increased trend in maternal morbidity 25,26 and justifies this fact due to the increase in cesarean sections, which require obstetric procedures and quality hospital care, 25 the South is one of the regions with the highest prevalences of Cesarean section in the Brazilian regions. ${ }^{23}$ In addition to, despite a similar trend in the North region, one of the least developed regions in the country, the overall rates in the South present lower values than in the North.

Also in the South, Paraná and Santa Catarina presented trends similar to some of the States in the more developed regions, such as São Paulo and the Federal District with a declining trend after a period of increase. It is important to highlight that the rising rates in these states in the initial years of the period analyzed may be due to the improvement in the information registrations, and the decrease in the second period for better care conditions and human development. The quality of obstetric care is the focus of maternal health discussion, and strengthening health systems is essential for reducing the most tragic maternal outcomes. ${ }^{27}$

For the Northeast of Brazil, the increase trend in maternal near miss rates may be explained by factors similar to those in the North region: inadequate maternal care, such as the need for the pregnant woman go to several public hospitals before being admitted for childbirth 28 and indicators of poor development. The main difference in relation to the North is that the rates have lower values in most of the States. Alagoas, Maranhão and Paraíba presented a decreased trend after the joinpoint, but were not significant, while Piauí, Ceará, Rio Grande do Norte and Pernambuco presented significant increases after the joinpoint. This trend may also be influenced by the increase in the notifications. A study conducted in Brazil on maternal mortality observed an increased trend in the North and Northeast 29 in recent years, possibly due to the improved quality in the information registrations.

The North region has the highest maternal near miss rates. With the exception for Amazonas and Amapá, all the States presented an increased trend of these rates. However, in Amazonas State, despite the decreasing trend after the joinpoint, the rates are still very high, as reported in another study, which identified elevated near miss rates in women that used the public health services in this State. 28 The most worrisome States were Roraima, Rondônia and Tocantins, which have presented a significant increase from 2007 onwards. In addition to a significant increase in both periods of the trend, Tocantins still registers the highest rates among the States in the North. Despite better maternal-infant care indicators, this region still needs to improve health care conditions and has the worst human development index, which may be influencing this scenario.

Another important point to consider is the use of the SIH-SUS as a routine to identify and monitor maternal near miss cases in reference services in the institutions, which may be an excellent alternative for investigating maternal health, since the system has widen the coverage and makes its information readily available in a short period.16,18 A study conducted in Canada, using routine hospital data and identified cases of maternal morbidity based on ICD10 codes, reinforcing the simplicity and rapidity in obtaining data, in addition to highlight excellent cost-effectiveness. 30 The greatest challenge is to convince managers to use the SIH not only as a regu- 
lator of payments for services rendered but also for epidemiological surveillance.

The main limitation of this study was the use of secondary data, especially in relation to the first years of the historical series, in which the rates in many States may have been influenced by the quality of the registrations. This is because one of the main criticisms of the SIH-SUS is the low reliability of information regarding diagnoses and procedures, resulting from the underlying rationale for using the system, which is linked more to paying the Health Units for the care provided than epidemiological surveillance itself. However, it is important to highlight that the system provides broad coverage and was not conceived only as a strategy to obtain resources, but rather as a potential disease surveillance tool.

As such, we conclude that there is still an increased trend in maternal near miss rates in Brazil and this trend behaves differently depending on the development level in the region studied presenting a positive and higher increase in less developed regions and States. The Northeast and North have presented increased rates for similar reasons, namely inadequate maternal care and indicators of poor development. The Southeast and Central-West, demonstrate a decreased trend in rates due to better effective maternal health care. An increase was observed in most States, especially in the first years of the historical series assessed, likely influenced by the improved quality of hospital registrations. Thus, investments are needed to improve SIH-SUS registrations in which may be an important tool in identifying and monitoring maternal morbidity, thereby strengthening epidemiological surveillance and maternal care. Furthermore, investments in more effective public policies are essential to reduce inequalities and improve human development, both of which have influenced the chain of events in maternal health.

\section{References}

1. WHO. Trends in Maternal Mortality: 1990-2013. Estimates by WHO,UNICEF, UNFPA, The World Bank and the United Nations Population Division. World Heal Organ. 2014 [acesso em 15 set 2016]. 56p. Disponível em: http://apps.who.int/iris/bitstream/10665/112682/2/9789241 507226_eng.pdf?ua $=1$.

2. Say L, Souza JP, Pattinson RC. Maternal near miss-towards a standard tool for monitoring quality of maternal health care. Best Pr Res Clin Obs Gynaecol. 2009; 23 (3): 287-96.

3.Filippi V, Ronsmans C, Campbell OM, Graham WJ, Mills A, Borghi J, Koblinsky M, Osrin D. Maternal health in poor countries: the broader context and a call for action. Lancet. 2006; 368 (9546): 1535-41.

4. Tunçalp O, Hindin MJ, Souza JP, Chou D, Say L. The prevalence of maternal near miss: a systematic review. BJOG. 2012; 119 (6): 653-61

5. Cirelli JF, Suritta FG, Costa ML, Parpinelli MA, Haddad SM, Cecatti JG. The Burden of Indirect Causes of Maternal Morbidity and Mortality in the Process of Obstetric Transition: A Cross-Sectional Multicenter Study. Rev Bras Ginecol Obstet. 2018; 40 (3): 106-18.

6. Sousa MH, Cecatti JG, Hardy EE, Amaral E, Souza JPD, Serruya S. Sistemas de informação em saúde e monitoramento de morbidade materna grave e mortalidade materna. Rev Bras Saúde Matern Infant. 2006; 6 (2): 161-8.

7. Geller SE, Koch AR, Garland CE, MacDonald EJ, Storey F, Lawton B. A global view of severe maternal morbidity: moving beyond maternal mortality. Reprod Health. 2018; 15 (Supl. 1): 98

8. Souza JP, Cecatti JG, Parpinelli MA, Serruya SJ, Amaral E. Appropriate criteria for identification of near-miss maternal morbidity in tertiary care facilities: a cross sectional study. BMC Pregnancy Childbirth. 2007; 7 (20): 1-8.
9. Moraes AP, Barreto SM, Passos VM, Golino PS, Costa JE, Vasconcelos MX. Severe maternal morbidity: a casecontrol study in Maranhao, Brazil. Reprod Health. 2013; 10 (11): 1-8.

10. Souza JP, Sousa MH, Parpinelli MA, Amaral E, Cecatti JG. Self-reported maternal morbidity and associated factors among Brazilian women. Rev Assoc Med Bras. 2008; 54 (3): 249-55.

11. Souza JP, Cecatti JG, Parpinelli MA, Sousa MH, Lago TG, Pacagnella RC, Camargo RS. Maternal morbidity and near miss in the community: findings from the 2006 Brazilian demographic health survey. BJOG. 2010; 117(13): 1586-92.

12. Mantel GD, Buchmann E, Rees H, Pattinson RC. Severe acute maternal morbidity: a pilot study of a definition for a near-miss. Br J Obs Gynaecol. 1998; 105 (9): 985-90.

13. Waterstone M, Bewley S, Wolfe C. Incidence and predictors of severe obstetric morbidity: case-control study. BMJ. 2001; 322 (7294): 1084-9.

14. Sousa MH, Cecatti JG, Hardy EE, Serruya SJ. Severe maternal morbidity (near miss) as a sentinel event of maternal death. An attempt to use routine data for surveillance. Reprod Health. 2008; 5 (6): 1-8.

15. Magalhães MC, Bustamante-Teixeira MT. Morbidade materna extremamente grave: uso do Sistema de Informação Hospitalar. Rev Saúde Pública. 2012; 46 (3): 472-8.

16. Magalhães MC, Raymundo CE, Bustamante-Teixeira MT. Morbidade materna extremamente grave a partir dos registros de internação hospitalar do Sistema Único de Saúde: algoritmo para identificação dos casos. Rev Bras Saúde Mater Infant. 2013; 13 (1): 17-22. 
17. Nakamura-Pereira M, Mendes-Silva W, Dias MAB, Reichenheim ME, Lobato G. Sistema de Informações Hospitalares do Sistema Único de Saúde (SIH-SUS): uma avaliação do seu desempenho para a identificação do nea miss materno. Cad Saúde Pública. 2013; 29 (7): 1333-45.

18. Bittencourt SA, Camacho LAB, Leal MC. A qualidade da informação sobre o parto no Sistema de Informações Hospitalares no Município do Rio de Janeiro, Brasil, 1999 a 2001. Cad Saúde Pública. 2008; 24(6): 1344-54.

19. Lobato G, Nakamura-Pereira M, Mendes-Silva W, Dias MA, Reichenheim ME. Comparing different diagnostic approaches to severe maternal morbidity and near-miss: a pilot study in a Brazilian tertiary hospital. Eur J Obs Gynecol Reprod Biol. 2013; 167 (1): 24-8.

20. Souza JP, Cecatti JG, Haddad SM, Parpinelli MA, Costa ML, Katz L, Say L; Brazilian Network for Surveillance of Severe Maternal Morbidity Group; Brazilian Network for Surveillance of Severe Maternal Morbidity. The WHO maternal near-miss approach and the maternal severity index model (MSI): tools for assessing the management of severe maternal morbidity. PLoS One. 2012; 7 (8): e44129.

21. Szwarcwald CL, Escalante JJC, Rabello Neto DL, Souza Junior PRB, Victora CG. Estimação da razão de mortalidade materna no Brasil, 2008-2011. Cad Saúde Pública. 2014; 30 (Supl. 1): S71-83.

22. Leal MC, Szwarcwald CL, Almeida PVB, Aquino EML, Barreto ML, Barros F, Victora C. Saúde reprodutiva, materna, neonatal e infantil nos 30 anos do Sistema Único de Saúde. Ciênc Saúde Coletiva. 2018; 23 (6): 1915-28.

23. Leal MC, Pereira APE, Domingues RMSM, Filha MMT, Dias MAB, Nakamura-Pereira M, Bastos MH, Gama SGN. Intervenções obstétricas durante o trabalho de parto e parto em mulheres brasileiras de risco habitual. Cad Saúde Pública. 2014; 30 (Supl. 1): S17-32.
24. Mendes JDV, Osiano VLRL. A Mortalidade Materna no Estado de São Paulo. Bepa. 2013;10(114):17-29.

25. Kuklina EV, Meikle SF, Jamieson DJ, Whiteman MK, Barfield WD, Hillis SD, Posner SF. Severe obstetric morbidity in the United States: 1998-2005. Obstet Gynecol. 2009; 113 (2 Pt 1): 293-9.

26. Fridman M, Korst LM, Chow J, Lawton E, Mitchell C, Gregory KD. Trends in maternal morbidity before and during pregnancy in California. Am J Public Health. 2014; 104 (Supl. 1): S49-57.

27. WHO (World Health Organization). Delivering quality health services: a global imperative for universal health coverage; $2018.100 \mathrm{p}$.

28. Cecatti JG, Souza RT, Pacagnella RC, Leal MC, Moura EC, Santos LMP. Maternal near miss among women using the public health system in the Amazon and Northeast regions of Brazil. Rev Panam Salud Publica. 2015; 37(4/5): 232-8.

29. Rodrigues NC, Monteiro DL, Almeida AS, Barros MB, Pereira Neto A, O’Dwyer G, Andrade MK, Flynn MB, Lino VT. Temporal and spatial evolution of maternal and neonatal mortality rates in Brazil, 1997-2012. J Pediatr (Rio J.) 2016; 92 (6): 567-73.

30. Joseph KS, Liu S, Rouleau J, Kirby RS, Kramer MS, Sauve R, Fraser WD, Young DC, Liston RM. Severe Maternal Morbidity in Canada, 2003 to 2007: Surveillance Using Routine Hospitalization Data and ICD-10CA Codes. J Obstet Gynaecol Canada. 2010; 32 (9): 837-46.

Received on March 31, 2018

Final version presented on November 12, 2018

Approved on December 26, 2018 